\title{
Prácticas cartográficas para una geografía feminista: los mapas como herramientas críticas
}

\author{
Núria Font-Casaseca \\ Universitat de Barcelona. Departamento de Geografía Humana \\ nuriafont@ub.edu
}

\section{Resumen}

Los cambios tecnológicos y conceptuales experimentados por la cartografía y los sistemas de información geográfica (SIG) en las últimas décadas han redefinido el papel y las posibilidades de los mapas como herramientas de investigación. En este artículo analizamos las contribuciones producidas en el contexto de las geografías feministas para recalibrar el papel y el potencial de las representaciones cartográficas actuales. Por un lado, sus propuestas han logrado afirmar la necesidad de adoptar una posición reflexiva hacia los mapas, tanto en el momento de su producción como en su uso y efectos. Por otro lado, la apropiación de estas tecnologías cartográficas desde posiciones feministas ha logrado transformar las prácticas cartográficas de manera aplicada y estratégica. Al convertirlas en tecnologías compatibles con sus principios, contienen un enorme potencial para toda persona o colectivo que utilice los mapas y los SIG como herramientas críticas y emancipadoras.

Palabras clave: SIG cualitativo; visualización feminista; cartografía crítica; reflexividad; geografía feminista

Resum. Pràctiques cartogràfiques per a una geografia feminista: els mapes com a eines crítiques

Els canvis tecnològics i conceptuals experimentats per la cartografia i els sistemes d'informació geogràfica (SIG) en les darreres dècades han redefinit el paper i les possibilitats dels mapes com a eines de recerca. En aquest article analitzem les contribucions produïdes en el context de les geografies feministes per revisar el paper i el potencial de les representacions cartogràfiques actuals. D'una banda, les seves propostes han aconseguit afirmar la necessitat d'adoptar una posició reflexiva cap als mapes, tant en el moment de la seva producció com en el seu ús i efectes. D'altra banda, l'apropiació d'aquestes tecnologies cartogràfiques des de posicions feministes ha aconseguit transformar les pràctiques cartogràfiques d'una manera aplicada i estratègica. En convertir-les en tecnologies compatibles amb els seus principis, contenen un enorme potencial per a tota persona o col-lectiu que utilitzi els mapes i els SIG com a eines crítiques i emancipadores.

Paraules clau: SIG qualitatiu; visualització feminista; cartografia crítica; reflexivitat; geografia feminista 
Résumé. Cartes et systèmes d'information géographique pour une géographie féministe: une vision de la cartographie critique

Les changements technologiques et conceptuels dont la cartographie et les systèmes d'information géographique (SIG) ont fait l'objet au cours des dernières décennies ont redéfini le rôle et les possibilités des cartes en tant qu'outils de recherche. Cependant, c'est dans certains domaines de la géographie féministe que des réflexions et des contributions parmi les plus profondes et les plus influentes ont été produites pour recalibrer le rôle et le potentiel des représentations cartographiques. D'une part, leurs propositions ont réussi à affirmer la nécessité d'adopter une position réflexive vis-à-vis de leur utilisation. Par ailleurs, l'engagement et l'appropriation de ces technologies cartographiques par des positions féministes ont permis de transformer ces outils et de les convertir en technologies de recherche compatibles avec leurs principes ainsi qu'avec un potentiel critique énorme pour toute personne ou tout groupe utilisant des cartes et des SIG.

Mots-clés: SIG qualitatif ; visualisation féministe ; cartographie critique ; réflexivité ; géographie féministe

Abstract. Maps and geographic information systems for a feminist geography: A vision from critical cartography

The technological and conceptual changes experienced by cartography and geographic information systems (GIS) in recent decades have redefined the role and potential of maps as research tools. However, it is in some areas of feminist geography where some of the most profound and influential reflections and contributions to recalibrate the role and potential of cartographic representations have occurred. On the one hand, their proposals have managed to affirm the need to adopt a reflective position towards their use. On the other hand, the commitment and appropriation of these cartographic technologies from feminist positions have managed to transform these tools and convert them into research technologies compatible with feminist principles and also with an important critical potential for any person or groups that use maps and GIS.

Keywords: Qualitative GIS; feminist visualization; critical cartography; reflexivity; feminist geography

\section{Sumario}

1. Introducción 3. Contribuciones feministas para una

2. Hacia unas prácticas cartográficas renovación de las prácticas cartográficas

feministas 4. Reflexiones finales

Referencias bibliográficas

\section{Introducción}

Es bien conocido que las transformaciones tecnológicas y conceptuales que se han venido produciendo en relación con la cartografía en los últimos años han hecho repensar el papel que pueden tener los mapas y las prácticas car- 
tográficas como herramientas de investigación ${ }^{1}$. Por un lado, la transición digital ha transformado profundamente las tecnologías cartográficas, los Sistemas de Información Geográfica (SIG) y el modo como los datos geográficos son recogidos, clasificados, analizados y visualizados, de manera que ofrecen nuevas oportunidades a aquellas personas y colectivos que utilizan de manera creciente los mapas para representar distintos aspectos del territorio. Por otro lado, sin embargo, como a menudo se ha denunciado desde la cartografía y los SIG críticos, las representaciones cartográficas son herramientas de investigación problemáticas porque siempre ofrecen miradas necesariamente parciales e interesadas sobre la realidad (Pickles, 2004). Así, aunque las innovaciones tecnológicas y digitales actuales hayan ampliado las posibilidades cartográficas, ello no es óbice para que no sea imprescindible al mismo tiempo adoptar una aproximación reflexiva sobre la naturaleza y los efectos de su uso, que preste atención a lo que los mapas nos dicen, pero también a cómo lo dicen, a lo que no nos están contando y a qué efectos pueden tener los procesos y las representaciones cartográficas sobre la realidad que tratan de representar.

En este artículo analizamos las reflexiones y contribuciones realizadas desde la geografía feminista a este debate. Esta aproximación a la geografía, que se ha desarrollado con rapidez desde los años 1980 gracias al influjo del pensamiento feminista, trata de incorporar y representar las diferentes y diversas experiencias de aquellos colectivos sociales en cierta medida invisibles en la investigación geográfica tradicional y, a la vez, pretende generar estrategias para desarrollar sus investigaciones de acuerdo con sus principios teóricos (Garcia Ramon, 1989). Uno de los campos sobre los que una parte de la geografía feminista ha centrado su interés ha sido la consideración de las imágenes, la cartografía y los SIG como metodologías de producción de conocimiento científico que, aun siendo problemáticas, tienen a la vez un gran potencial para sus intereses. Las distintas reflexiones y contribuciones realizadas en este contexto pueden servir de ejemplo para comprender el potencial innovador y, al mismo tiempo, crítico que ofrece la cartografía digital actual, al haber sabido combinar un análisis profundo sobre la naturaleza y limitaciones de los mapas con el desarrollo de diversas propuestas y aplicaciones que aprovechan las nuevas posibilidades tecnológicas y digitales de manera compatible con los principios de la investigación feminista.

Estas aportaciones han tenido lugar en el contexto de una relación compleja entre la cartografía y la geografía. Por un lado, los mapas están más presentes que nunca en numerosos ámbitos académicos y ciudadanos, y los SIG se han convertido en una herramienta central e imprescindible para la geografía aplicada. Por otro lado, en las últimas décadas, el mapa parece haber ido perdiendo

1. En este artículo hablamos de "prácticas cartográficas» como un concepto que engloba los mapas, los SIG y todos aquellos procesos cartográficos necesarios para la producción de un mapa y que van más allá de la propia representación cartográfica. En el contexto tecnológico actual, el análisis y la difusión de los datos geográficos ya no solo se producen a través del mapa entendido como un objeto en papel estable y estático. Ahora, la información también puede analizarse y visualizarse de manera interactiva y dinámica a través de pantallas. 
peso como herramienta analítica y comunicativa para la geografía académica al mismo tiempo que surgían profundas reflexiones críticas sobre la cartografía y su papel en la sociedad (Dodge y Perkins, 2008). Esta contradicción resulta cuando menos sorprendente dada la importancia y la tradición histórica que han tenido los mapas para la geografía, considerados en su momento como su «lenguaje» característico (Raisz, 1948; Sauer, 1956). Algunas de las razones que se han señalado para explicar esta pérdida de centralidad del mapa como herramienta de investigación y comunicación geográfica han sido: los retos producidos por los cambios que ha supuesto la transición digital, las dificultades metodológicas para representar con mapas los complejos conceptos y procesos con los que se enfrenta la geografía actual y, finalmente, la propia diversidad de posiciones teóricas hacia la naturaleza de los mapas y su utilidad para producir conocimiento científico (Martin, 2000). En este sentido, una de las ideas que más ha contribuido a cuestionar el uso de los mapas y los SIG, especialmente por parte de los estudios geográficos críticos, procede de la vinculación que la geografía radical habría establecido, desde los años setenta, entre positivismo y cuantificación (Barnes, 2009), expresada también en la aparente incompatibilidad entre lo cuantitativo y lo radical (Smith, 1979). A partir de ese momento, la división entre geógrafos teóricos críticos y aquellos que utilizan metodologías cuantitativas, análisis espacial y por extensión los SIG y las prácticas cartográficas no parece sino haberse acrecentando (Kwan, 2004). Estos desencuentros entre la cartografía y las disciplinas geográficas se han traducido en una cierta división y desconexión entre todas aquellas personas, campos y disciplinas involucrados de alguna manera con los mapas y la investigación geográfica, en especial desde perspectivas críticas (Benach, 2017).

En medio de todo este debate, la geografía feminista ha sido capaz no solo de realizar reflexiones profundas sobre las limitaciones de los mapas como herramientas analíticas, sino también de hacer propuestas capaces de reconciliar estas dos esferas aparentemente conflictivas (la geografía crítica y la cartografía), tanto en el ámbito teórico como en el práctico. Teniendo en cuenta lo anterior, este artículo tiene como principal objetivo identificar las principales aportaciones producidas desde la geografía feminista para repensar las prácticas cartográficas como herramientas de investigación o participación críticas. A través de la identificación de algunas de sus propuestas, se destacan algunas de las posibilidades que esta aproximación ha abierto para encontrar nuevas maneras de utilizar estas herramientas visuales. La cuestión de fondo al estudiar las aportaciones de la geografía feminista a las prácticas cartográficas actuales no es solo comprender qué puede aportar su uso a aquellas investigadoras que aún no usan los mapas, sino cómo sus aportaciones pueden llegar a transformar de manera general el modo en que elaboramos y utilizamos los mapas en otros ámbitos, a través de la incorporación de algunas reflexiones, conceptos y estrategias propios de la investigación feminista. Con este objetivo, en la segunda parte del artículo se identifican tres estrategias inspiradas por estas prácticas cartográficas feministas que pueden ser útiles también para el conjunto de ámbitos y personas, tanto dentro como fuera de la academia, que 
utilizan la cartografía como herramienta de investigación o participación y que están preocupadas por visibilizar y dar voz a las experiencias de las mujeres y otros colectivos que han sido sistemáticamente silenciados o ignorados en las representaciones cartográficas, y que pueden encontrar en estas una herramienta crucial para sus intereses.

\section{Hacia unas prácticas cartográficas feministas}

La crítica a las herramientas visuales y a su supuesta objetividad ha sido uno de los objetos de atención de la geografía feminista. En esta aproximación, que ha sido compartida también por otros investigadores, las geógrafas feministas han denunciado la posición privilegiada y dominante que la cultura occidental ha asignado al sentido de la vista en detrimento de los otros sentidos, una posición útil para legitimar y perpetuar relaciones de dominación y de poder (Foucault, 1980), el colonialismo (Said, 1978) o determinadas representaciones del paisaje (Cosgrove, 1984). Bajo la perspectiva feminista, los esfuerzos se han centrado en señalar el carácter «situado» del conocimiento científico (Haraway, 1988), a pesar de que la existencia de tecnologías visuales externas (como los microscopios, los satélites o la fotografía), que facilitan y mejoran la visualización, haya consolidado justamente la falsa ilusión de que es posible una visión objetiva y universal. Esta perspectiva ha situado a las imágenes visuales (y por extensión a los mapas) en un papel central en la consolidación de una perspectiva «masculina» de la disciplina geográfica que, a través de estos dispositivos visuales, oculta su ideología, sus intereses y su responsabilidad (Rose, 2003). Desde la década de los noventa, el interés se ha venido dirigiendo también de manera explícita hacia los Sistemas de Información Geográfica, sobre todo en lo que se refiere a las implicaciones sociales, éticas y políticas de unas tecnologías que en aquel momento se hallaban en pleno desarrollo y que estaban estrechamente vinculadas al poder y al control militar (Pickles, 1995; Schuurman, 2000; Leszczynski, 2009; Thatcher et al., 2015).

Aunque tanto las críticas como el abandono de la cartografía por parte de un sector de la geografía han continuado en cierta medida hasta la actualidad (Kwan, 2002a; McLafferty, 2010), desde los años 1980 también se empezaron a establecer algunos puentes entre estas posiciones aparentemente irreconciliables. Así, se empezaron a realizar descripciones empíricas de las diferencias y particularidades de las experiencias de las mujeres, en ocasiones apoyadas en mapas, que ponían en evidencia el modo en que se estaba desarrollando la geografía en ese momento, y que implicaba de hecho una "exclusión» de la «mitad del género humano», al asumir la universalidad y homogeneidad de todas las personas (Monk y Hanson, 1982; Monk y Garcia Ramon, 1987). Con este objetivo, algunas geógrafas se empezaron a interesar por analizar y representar de manera cartográfica los espacios y las experiencias humanas desde un punto de vista de género y también en relación con la clase, la raza, la sexualidad y otros ejes relacionados. Esto supuso la producción de investigaciones y también de representaciones en las que las mujeres y sus experiencias 
Figura 1. Pautas de actividad cotidianas y localización de los lugares y personas de referencia de una mujer blanca y de otra afroamericana en la ciudad de Worcester

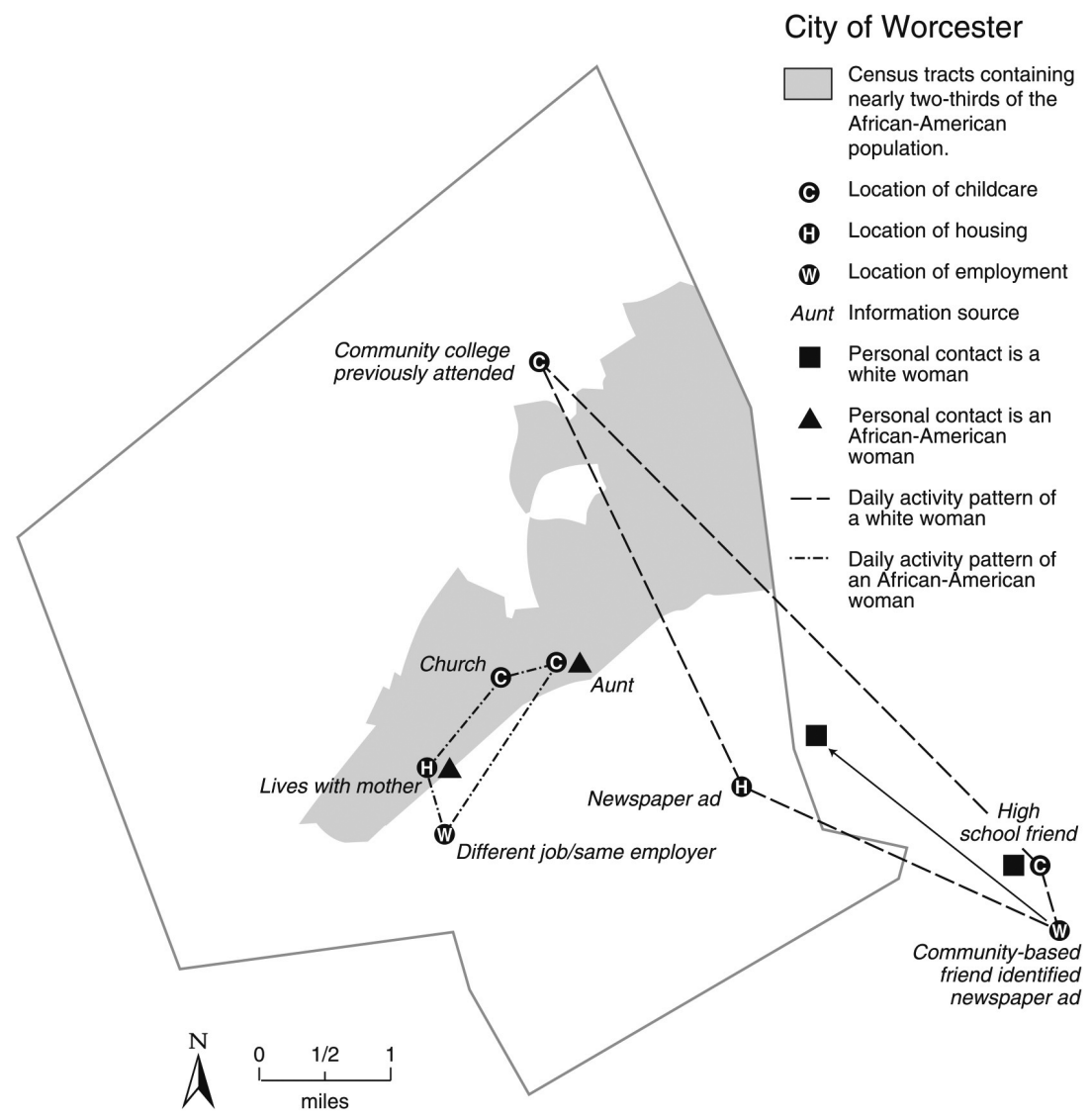

Fuente: Gilbert (2005: 615).

particulares se convirtieron en objetivos de la investigación geográfica. Un ejemplo es el Atlas del estado de la mujer en el mundo, donde su autora, Joni Seager, empezó a mostrar la realidad y las condiciones sociales y económicas de las mujeres en las distintas partes del mundo, lo que reveló problemáticas normalmente ocultas en los datos estadísticos oficiales y los mapas globales (Seager, 2001; 2018).

De manera complementaria, la geografía feminista también se empezó a interesar por visibilizar la dimensión cotidiana de nuestras vidas, no solo en un sentido descriptivo (como una dimensión complementaria a otras esferas más relevantes), sino incluyendo perspectivas que buscaban problematizar la vida humana y su estudio en todas sus dimensiones y escalas. Dado que la "pers- 
pectiva de la vida cotidiana» hace referencia no solo a una manera distinta de entender la realidad social sino también a todo un conjunto de metodologías capaces de estudiarla (Vaiou y Lykogianni, 2006: 735), algunas investigadoras empezaron también a utilizar mapas para revelar las diversas y complejas relaciones y experiencias espaciales de las mujeres. Un ejemplo fue la investigación de Melissa R. Gilbert, que analizó y representó en un mapa (figura 1) los contrastes espaciales y relacionales en las estrategias de supervivencia de las mujeres blancas y afroamericanas en sus actividades cotidianas (Gilbert, 2005). En este sentido, la aproximación feminista ha conseguido poner el foco de atención en las múltiples dimensiones, tiempos y escalas que caracterizan la vida humana (la vida doméstica o cotidiana, el cuerpo y la familia, la informalidad, los ciclos de vida, la enfermedad, los cuidados) y que a menudo habían quedado relegadas, cuando no silenciadas, en la investigación geográfica.

A pesar del interés en visibilizar estas experiencias a través de los mapas, desde el inicio se hizo evidente la dificultad de traducir unos fenómenos sociales complejos a un lenguaje cartográfico muy vinculado a una concepción cartesiana y euclidiana del espacio, que representaba a las personas y sus vivencias como puntos, líneas y polígonos, y utilizaba una categorización social, geográfica y escalar estable y fija (Bondi y Domosh, 1992; Sheppard et al., 1999). La cuestión que debía resolverse era cómo la geovisualización y los SIG, así como las metodologías cuantitativas en su conjunto, podían llegar a contribuir y enriquecer la investigación geográfica feminista de un modo compatible con sus objetivos y principios. Dado que la incorporación gradual de las experiencias y problemáticas de las mujeres y otros colectivos vulnerables u oprimidos como objetos cartográficos coincidió con una crítica profunda a la objetividad científica de las herramientas visuales, era necesario encontrar nuevas maneras de utilizar estas herramientas visuales de un modo compatible con los principios de la investigación feminista.

Estas cuestiones encontraron algunas respuestas en el debate más amplio que se había iniciado a principios de los años 1990 en torno a la relación entre la geografía crítica (y especialmente la geografía feminista anglosajona) y las metodologías cuantitativas, que hasta entonces habían pasado a un segundo plano ante la emergencia de lo cualitativo. Tras un periodo de abierto rechazo, algunas autoras empezaron a demostrar la utilidad de incorporar, a pesar de sus limitaciones y debilidades, los métodos cuantitativos para la investigación geográfica feminista (D. Rose, 1993; McLafferty, 1995; Moss, 1995; Rocheleau, 1995). Entre otros aspectos, su uso permitía cuantificar y situar en un contexto más amplio las problemáticas y reivindicaciones sobre las desigualdades sociales normalmente estudiadas a partir de casos concretos y puntuales; lo cuantitativo resultaba útil en una primera fase para identificar aquellos ámbitos de interés sobre los que centrar luego un análisis detallado; y de paso, al utilizar el «lenguaje del poder», también se podía obtener una mayor difusión y alcance de los resultados y reivindicaciones. Uno de los lugares privilegiados donde ensayar el potencial de combinar distintas metodologías fueron, precisamente, los mapas y los SIG. Para llevar a cabo este proceso, sin embargo, ha sido necesario 
repensar algunas de las ideas más extendidas sobre la naturaleza de las prácticas cartográficas. Como señala Kwan, la aparente conexión entre los métodos cartográficos y la epistemología positivista y masculina es «contingente», tanto histórica como espacialmente, y el hecho de que se haya utilizado mayoritariamente en contextos políticos y sociales afines a esas aproximaciones no implica que no puedan utilizarse de otras maneras (Kwan, 2002b).

Estas reflexiones han dado lugar al desarrollo de la denominada «visualización feminista" (Kwan, 2002b; Pavlovskaya, 2009a; D'Ignazio y Klein, 2016), entendida como un conjunto de estrategias, metodologías y reflexiones que tratan de desestabilizar las prácticas cartográficas dominantes, cuestionar los persistentes dualismos entre los métodos geográficos, identificar los sesgos y silencios que existen en las metodologías convencionales y considerar las visualizaciones como prácticas situadas y personales. Ello ha supuesto incorporar a las mujeres no solo como objetos de estudio en la cartografía, de la que habían estado ausentes, sino también como «sujetos» cartográficos (Pavlovskaya y Martin, 2007). Cabe señalar que esta participación activa en la producción cartográfica no era algo totalmente nuevo, ya que el uso de los mapas como herramienta de investigación para las mujeres ya contaba con pocos pero relevantes referentes históricos, por ejemplo, el desarrollado por las residentes de la Hull House de Chicago a finales del siglo XIx (Font-Casaseca, 2016). Sin embargo, el compromiso explícito con la transformación de las prácticas cartográficas desde dentro de la propia disciplina ha surgido con fuerza en los últimos años.

Uno de los ejemplos de este uso de los SIG como herramientas de investigación feministas ha sido la propuesta de las "geonarrativas» desarrollada por Mei Po Kwan (Kwan y Ding, 2008). Aunque la combinación de información etnográfica o cualitativa con datos geográficos o localizaciones espaciales ha sido una estrategia utilizada por diversos investigadores (Matthews et al., 2005; Watts, 2010; Verd y Porcel, 2012), la particularidad de su enfoque ha sido la integración de las tecnologías y análisis ligados a las metodologías cualitativas dentro de los propios SIG. Para ello, ha diseñado un componente complementario llamado 3D-VQGIS que permite codificar, visualizar y realizar análisis cualitativos y espaciales, extendiendo las capacidades analíticas de los SIG para incluir los materiales textuales y la localización de las actividades y los recorridos en el tiempo y el espacio.

Este tipo de estudios se inspira de manera explícita en el enfoque de la «time-geography» desarrollado por Torsten Hägerstrand, en el cual la representación cartográfica tenía un papel destacado (Hägerstrand, 1970). Su propuesta permitía realizar una aproximación compleja a las trayectorias individuales de cada persona a través de una sofisticada representación cartográfica y, al mismo tiempo, reivindicaba la importancia de considerar de manera combinada el espacio y el tiempo en la escala "micro», en la que se desarrollaba su vida cotidiana y que no había sido en absoluto considerada en los modelos espaciales del momento. Hägerstrand diseñó una representación capaz, por un lado, de registrar de una manera visual y sintética los componentes espaciales y 
temporales de las trayectorias y, por el otro, señalar las limitaciones e impedimentos a los movimientos que caracterizaban estas trayectorias vitales. Aunque el modelo fue criticado por algunas investigadoras por su simplificación y su «masculinidad» (G. Rose, 1993), en los últimos años, y gracias precisamente al desarrollo de técnicas digitales de representación, se ha empezado a utilizar fructíferamente en estudios centrados en las diferencias de movimiento entre géneros (rutinas cotidianas relacionadas con los cuidados y las tareas domésticas) o entre diferentes colectivos, e incluso para identificar restricciones emocionales relacionadas, por ejemplo, con el miedo o los prejuicios (Kwan, 1999; 2007; Kwan y Schwanen, 2016). Una ventaja de este tipo de análisis es la posibilidad de estudiar las experiencias vitales en torno a acontecimientos cotidianos o traumáticos, por ejemplo, en un período determinado de tiempo, y relacionarlas con sus contextos sociales, políticos, culturales y geográficos.

Uno de los casos de estudio desarrollados por Kwan ha sido el análisis del impacto que tuvieron algunos ataques antimusulmanes tras el 11-S en Estados Unidos para un grupo de 37 mujeres musulmanas en Columbus, Ohio (Kwan, 2008). El objetivo era investigar de qué modo había afectado e influido en sus vidas cotidianas el clima de hostilidad y odio hacia su comunidad, que las

Figura 2. Imagen del componente desarrollado por Mei-Po Kwan para extender las capacidades analíticas de los SIG para el análisis espaciotemporal y cualitativo

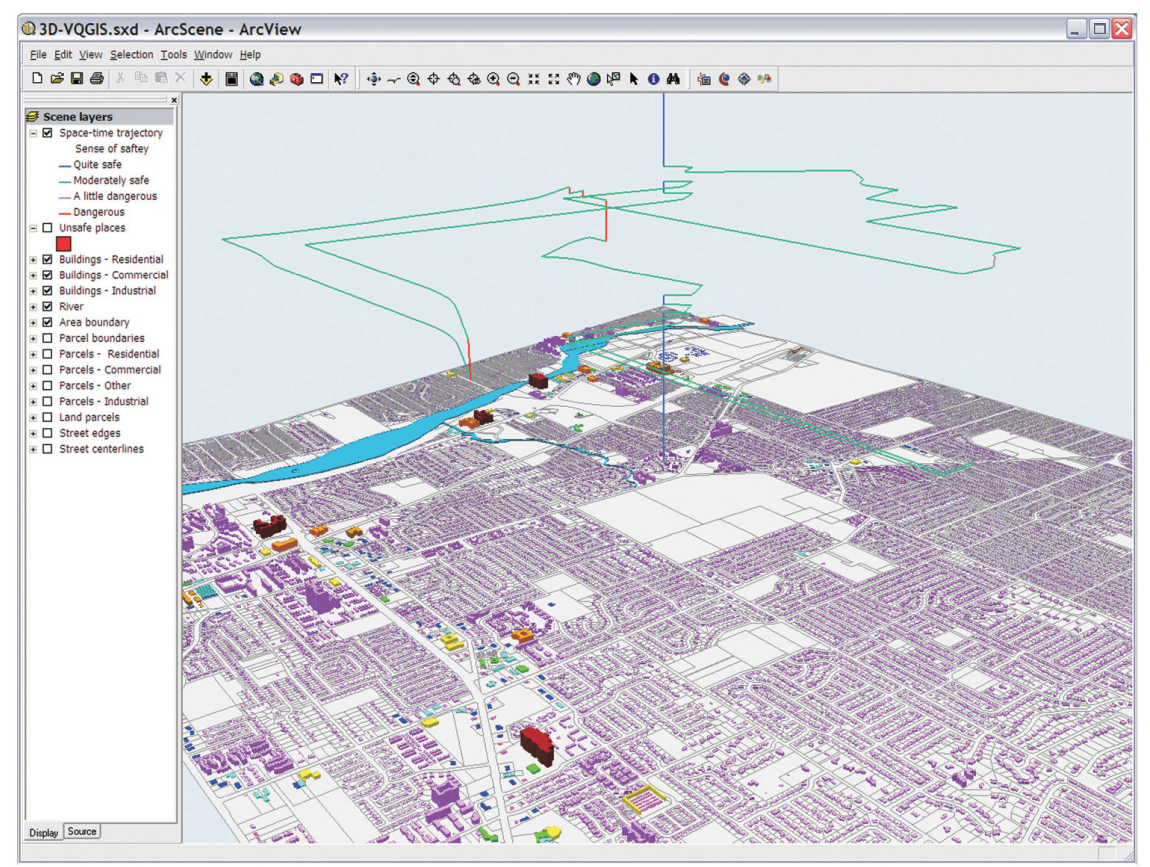

Fuente: Kwan y Ding (2008: 455). 
mujeres experimentaban en forma de vulnerabilidad, ataques y discriminación. Por un lado, ellas eran fácilmente reconocibles por su forma de vestir. Por otro lado, sus rutinas cotidianas en las tareas de cuidados limitaban sus alternativas (en forma de horarios y recorridos) ante los riesgos percibidos. La investigación recopiló información a partir de entrevistas personales sobre sus actividades diarias y sobre los cambios y las experiencias en torno al problema estudiado, lo que se materializó en un proyecto que integraba información espaciotemporal junto con material cualitativo. La geovisualización interactiva resultante se organizó en torno a una representación en 3D que permitía consultar y analizar de manera dinámica lugares, trayectos, duración de las actividades y movimientos en relación con las emociones de cada participante (figura 2). Además, desde el propio programa se puede consultar, codificar y analizar el material complementario, como las entrevistas, las imágenes y los enlaces.

\section{Contribuciones feministas para una renovación de las prácticas cartográficas}

Los casos y reflexiones descritos en el apartado anterior muestran el potencial que puede llegar a tener un uso crítico de los mapas y los SIG para la investigación social. De manera más sistemática, en este apartado destacamos tres contribuciones o estrategias inspiradas por esta llamada a reconciliar la geografía feminista con las prácticas cartográficas que pueden ser útiles para enriquecer el modo en que utilizamos y entendemos los mapas. En primer lugar, señalamos la importancia de adoptar una actitud reflexiva ante el proceso cartográfico y las limitaciones que tienen los mapas para representar la realidad. En segundo lugar, mostramos el potencial que pueden tener los Sistemas de Información Geográfica como herramientas mixtas, al permitir combinar datos y análisis cuantitativos y cualitativos. Finalmente, señalamos el papel crucial que pueden tener los mapas para convertirse en herramientas críticas y emancipadoras para determinados colectivos sociales interesados en transformar la sociedad y en visibilizar otros puntos de vista y experiencias sobre la misma.

\subsection{Reflexividad ante las prácticas cartográficas}

La primera característica común a muchas de las experiencias cartográficas producidas desde la geografía feminista (compartida también por las denominadas contracartografías ${ }^{2}$ ) es la adopción de una actitud reflexiva para producir y usar los mapas. La noción de reflexividad como estrategia de investigación, que reconoce la parcialidad del conocimiento científico y problematiza las

2. Las contracartografías consideran el proceso cartográfico como un acto intrínsecamente político (Peluso, 1995; Crampton y Krygier, 2005). La contracartografía puede entenderse como el uso activo del mapa y de las prácticas cartográficas como herramientas para cuestionar, denunciar o plantear alternativas ante una situación de opresión o conflicto (Harris y Hazen, 2005) y abarca un gran conjunto de experiencias, proyectos y reivindicaciones de colectivos diversos que aprovechan el "poder» de los mapas para contrarrestar sus efectos. 
relaciones de poder entre las investigadoras y el objeto de estudio, ha ocupado un papel central en los trabajos de las investigadoras feministas (England, 1994; Gibson-Graham, 1994; G. Rose, 1993; Nast, 1998). Su incorporación en la investigación feminista inició una profunda reflexión teórica y analítica sobre las implicaciones de adoptar un nuevo enfoque científico sensible a estas relaciones. Entre otras, significaba repensar aspectos como la posicionalidad en la producción del conocimiento científico; la importancia de introducir la diversidad, la diferencia y la interseccionalidad en los debates (Kobayashi, 1994; Valentine, 2007); el carácter socialmente construido de las categorías sociales y sus efectos (Kobayashi, 1997; Valentine y Sadgrove, 2012); y también el compromiso que debían adoptar estas nuevas aproximaciones con la emancipación social y con la reducción de la desigualdad y la opresión (Katz, 1996).

En el contexto específico de los SIG y la cartografía, la reflexividad requiere ser sensible al impacto que tienen las prácticas cartográficas sobre las personas y los colectivos investigados, y su aplicación ha tenido un gran efecto para el desarrollo de una nueva relación entre la investigación geográfica feminista crítica y las prácticas cartográficas. Además, como queremos remarcar aquí, esta perspectiva reflexiva puede llegar a enriquecer de manera importante nuestra comprensión sobre el poder y los efectos de los mapas como herramienta de investigación también en otros ámbitos. En su obra Visual Methodologies: An Introduction to the Interpretation of Visual Materials, Gillian Rose (2011) propone una aproximación crítica a las imágenes visuales atendiendo a la importancia cultural crucial que éstas tienen en la actualidad. Con este objetivo, la autora desarrolla un marco de análisis e interpretación de los materiales visuales centrado en los distintos «lugares» en los que se producen los significados: el lugar de producción, el lugar de la propia imagen y, finalmente, el lugar de la audiencia. Cada uno de estos lugares se caracteriza por unas determinadas condiciones tecnológicas (todas las técnicas y conocimientos necesarios para producir una imagen), composicionales (estrategias formales que articulan su construcción) y sociales (relaciones sociales, económicas, políticas, así como las creencias, herencias e intereses que rodean la producción de las imágenes). Trasladada a los SIG y los mapas, esta propuesta nos ofrece un marco de análisis para acercarnos a las prácticas cartográficas de una manera más compleja, y entenderlas al mismo tiempo como una tecnología, una metodología y una práctica social situada en un contexto específico. Desde una actitud reflexiva, esta propuesta nos permite, por ejemplo, contemplar los múltiples lugares desde los que las prácticas cartográficas determinan el tipo de mirada adoptada sobre la realidad. Estos lugares no se limitan al momento de producción de los mapas ni al de la propia representación, sino también al uso que hacemos de ellos. A este respecto, Cope y Elwood señalan la necesidad de entender los sistemas de información geográfica del siguiente modo:

... como práctica social y política, como maneras inscritas en la disciplina —e industria - de producir conocimiento, y como un ensamblaje de hardware, software, estructuras de datos, y procedimientos para trabajar con datos 
espaciales digitales. Esta conceptualización de los SIG nos permite considerar la producción de conocimiento basada en SIG como algo que está ocurriendo explícita e implícitamente en sitios diversos: datos espaciales, estructura de datos, análisis espacial, representación cartográfica, y la aplicación o uso de cualquiera de estos fenómenos en la práctica social y política. (Cope y Elwood, 2009: 3)

En primer lugar, pues, es necesario preguntarnos qué implicaciones tienen nuestras propias ideas y posición ante los mapas, así como qué intereses, tecnologías, metodologías, relaciones de poder y objetivos entran en juego en los procesos cartográficos. En segundo lugar, el análisis puede centrarse en el propio mapa para analizar la mirada particular que transmitimos con nuestras decisiones de representación. Desde esta perspectiva se pueden analizar, por ejemplo, las exclusiones, los silencios y las simplificaciones que realizan los mapas a través de la simbología, escala o delimitación espacial utilizada, y cómo las representaciones cartográficas reducen las personas, las relaciones y las experiencias a objetos espaciales. Aunque algunas de estas limitaciones son inevitables, en muchos casos es posible adoptar una posición activa y propositiva para seleccionar en cada momento el tipo de representación, datos y métodos más adecuados a cada fenómeno analizado, en lugar de dejar que sea la propia tecnología la que decida. Finalmente, otro aspecto sobre el cual es necesario reflexionar es qué influencia o efectos tienen las representaciones cartográficas. El mapa no es solo una representación particular (y limitada) de la realidad, sino que las imágenes tienen el poder de configurar nuestras percepciones e ideas sobre ella. Así, hay que preguntarse siempre si la representación elaborada ayuda o limita nuestra comprensión sobre el fenómeno estudiado, qué experiencias resultan excluidas, oprimidas, estigmatizadas o malinterpretadas en ella y de qué manera se podrían incluir en el proceso cartográfico otras voces (como sujetos activos y no solo como objetos representados) para que los mapas sean una herramienta emancipadora.

Los mapas han sido utilizados, por ejemplo, en los estudios queer en geografía para visibilizar una realidad a menudo oculta en los datos oficiales (Brown y Knopp, 2006; 2008; Gieseking, 2013). En su proyecto de investigación "Between Being and Looking...», Cieri (2003) analizó el espacio social de un grupo de lesbianas en Filadelfia, y la relación o discordancia que existía entre las imágenes "oficiales» que promocionaban el turismo gay en la ciudad y sus propias experiencias. Este proyecto se inscribe en la búsqueda de la autora de nuevas herramientas para contar las «historias geográficas» de las personas implicadas en primera persona y no mediadas por voces «autorizadas», por ejemplo, mapas y datos oficiales. Los resultados muestran, por un lado, la fuerte relación entre la promoción de espacios gay y el consumo capitalista (en su mayoría bares, comercios o discotecas). Y por otro, la comparación entre estos espacios y aquellos identificados por las entrevistadas demuestra la necesidad de cuestionar unas representaciones sobre la homosexualidad urbana que no son capaces de recoger gran parte de las experiencias y lugares particulares de las mujeres lesbianas y bisexuales. 


\subsection{Los SIG como herramientas cualitativas y «mixtas»}

En segundo lugar, una de las aportaciones con mayor potencial para repensar el uso actual de los mapas y los SIG en la investigación académica ha sido cuestionar el supuesto carácter cuantitativo de las herramientas y tecnologías cartográficas. Como señala Pavlovskaya, la percepción de que los SIG y los mapas son necesariamente de corte positivista y cuantitativo se basa en ideas confusas y erróneas sobre estos, porque de hecho solo una pequeña parte de los procesos o funciones de los SIG son análisis espaciales "complejos» en un sentido cuantitativo (Pavlovskaya, 2006; 2009b). La mayoría de los usos de los SIG suelen utilizar funciones y análisis espaciales bastante básicos que requieren ante todo imaginación geográfica, pensamiento lógico y una cierta intuición espacial, algo común en todo trabajo geográfico. Por ello, en los últimos años han ido apareciendo diversas propuestas e investigaciones que demuestran el potencial que supone utilizar la capacidad de los SIG y los mapas para combinar datos y metodologías cuantitativas y cualitativas (Suchan y Brewer, 2000; Knigge y Cope, 2009; Boschmann y Cubbon, 2014; Mennis et al., 2013; Schoepfer y Rogers, 2014; Preston y Wilson, 2014).

Esta «multiperspectiva» metodológica ha encontrado en los mapas y los SIG un lugar importante desde el cual abrir un nuevo espacio «epistemológico» capaz de combinar métodos considerados tradicionalmente como cuantitativos (como la estadística, la cartografía o los SIG) con la interpretación de las historias personales, el análisis del discurso y los métodos participativos (Rocheleau, 1995). En este contexto, el mapa juega un papel de intermediario entre distintas metodologías (cuantitativas y cualitativas) que, combinadas, consiguen una visión más completa y contextualizada que la que se podría obtener utilizando una única forma de producir conocimiento. Precisamente, una de las ventajas de la triangulación es la "complementariedad» entre las fuentes de datos utilizadas (Hoggart et al., 2002). Dado que cada metodología y cada fuente de información tienen sus propias limitaciones, sesgos y posibilidades, la combinación de fuentes de datos distintas permite identificar diferentes facetas de un mismo problema proporcionando una validación cruzada. Desde una perspectiva abierta a la combinación entre distintos métodos, la investigación se enriquece y se convierte en un proceso dinámico que permite contrastar, cuestionar, complementar y enfrentar varias maneras de entender una misma realidad.

La combinación de las capacidades de los SIG con los métodos y análisis cualitativos ha permitido ampliar el poder analítico y representacional de los SIG y, al mismo tiempo, sortear sus limitaciones relativas a ciertas formas de análisis (Pavlovskaya, 2009b). Así, al hablar de SIG «cualitativos» no solo hacemos referencia a la incorporación de información cualitativa (en forma de texto, imágenes o audios) a las representaciones cartográficas, sino también a realizar una reflexión profunda sobre los SIG y sobre cómo entender lo «cualitativo» en un contexto digital. Para Cope y Elwood, lo que caracteriza la información cualitativa no es solo su carácter no numérico, sino el tipo de 
información que aporta sobre el contexto social y material de las situaciones y fenómenos analizados, así como las distintas interpretaciones de los implicados a los procesos descritos. Este tipo de información complementa el conocimiento "frío» de los datos cuantitativos y permite identificar las distintas facetas, contradicciones y múltiples «verdades» posibles ante un mismo fenómeno (Cope y Elwood, 2009).

Un resultado de esta redefinición de lo cualitativo en los sistemas de información geográfica ha sido el desarrollo de la denominada «visualización fundamentada" (grounded visualization), un tipo particular de metodología analítica e integradora que utiliza de manera integrada los SIG y la etnografía (Knigge y Cope, 2006). Esta propuesta combina la «geovisualización» y la «teoría fundamentada». La geovisualización es una aproximación que permite explorar de manera visual conjuntos de datos espaciales e identificar pautas, relaciones y tendencias de una manera dinámica e interactiva (MacEachren y Kraak, 2001). En la teoría fundamentada, una metodología procedente de la antropología y la sociología, el proceso de investigación, categorización y codificación se plantea de manera dinámica y flexible a medida que avanza la investigación (Glaser et al., 1968). Al combinar ambas en los SIG, los datos cuantitativos y cualitativos son analizados y «explorados» de manera visual y dinámica, lo que da cabida a múltiples interpretaciones del mundo de manera simultánea. Esto los convierte en lugares capaces de producir conocimiento «situado» sobre las distintas experiencias reales y cotidianas y, al mismo tiempo, ponerlas en relación con otros procesos, contextos y escalas (Knigge y Cope, 2006). La facilidad para trabajar a distintas escalas en un entorno SIG resulta muy útil para analizar conjuntos de datos de manera compleja y con distintas resoluciones, ya que permite modificar de forma dinámica las unidades de agregación de los datos y trabajar a distintas resoluciones espaciales.

Un ejemplo de su utilidad ha sido la investigación desarrollada por Knigge y Cope sobre los «huertos comunitarios» del Lower West Side de Buffalo (Nueva York), una zona con unas organizaciones sociales bastante activas y caracterizada por su diversidad social y étnica, unas tasas altas de criminalidad, viviendas abandonadas y un sector comercial en declive. El objetivo de la investigación era identificar algunas estrategias comunitarias desarrolladas por sus habitantes ante una situación urbana problemática, y cómo estas acciones redefinían la identidad, las prácticas sociales y el sentido de pertenencia de los habitantes del barrio. Los datos obtenidos del trabajo de campo y del análisis estadístico (datos censales, fotografías, entrevistas, vínculos a otros documentos externos o notas propias) fueron localizados y organizados en un SIG (figura 3). El análisis de todo este material diverso permitió explorar las características y las múltiples representaciones e interpretaciones existentes sobre la zona, así como identificar aspectos comunes o contradictorios entre ellos, por ejemplo, en relación con los procesos de categorización de la información recogida. Una muestra de ello es el uso que los distintos implicados hacen del concepto vacío urbano. Para las autoridades, el carácter vacío de un espacio está vinculado al uso que hacen de él sus propietarios, aunque a distintas escalas puede tener 
Figura 3. Ejemplo de las múltiples representaciones del Lower East Side de Buffalo (NY) que permite la «visualización fundamentada»

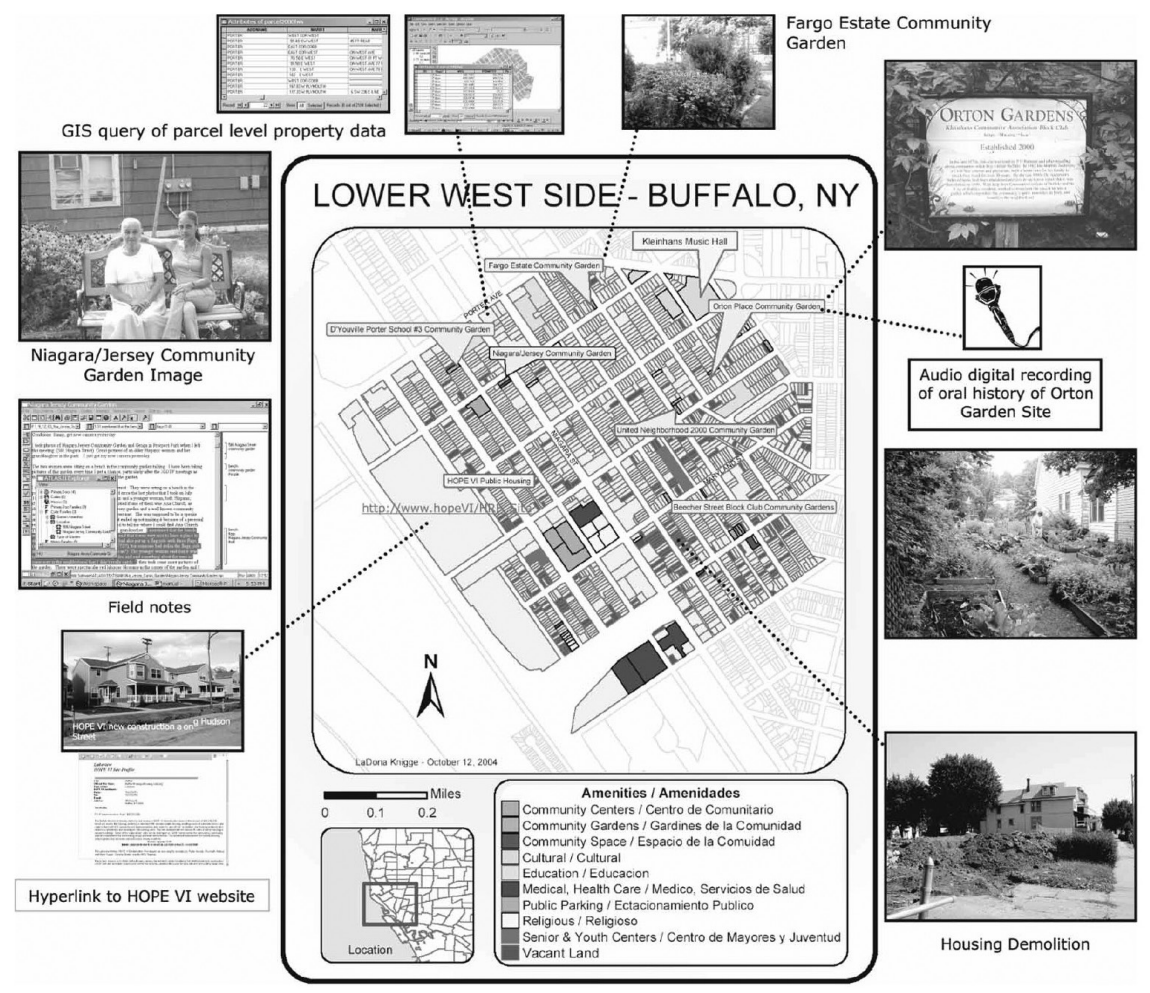

Fuente: Knigge y Cope (2006).

diferentes connotaciones y delimitaciones (desde una parcela individual a una parte de la ciudad a la que se requiere asignar un nuevo uso). Sin embargo, si incorporamos a estas definiciones de vacío otro tipo de significados, los vacíos urbanos pueden ser vistos como una oportunidad (en épocas de crecimiento económico) o como un problema (en economías en declive). Además, para los vecinos, el concepto vacio puede no estar ligado a la propiedad de las parcelas. Muchos de los espacios comunitarios del ámbito no son considerados en absoluto vacíos por aquellos que los ocupan y utilizan, y algunos de ellos están cargados de significados, historia y memorias para sus habitantes (Knigge y Cope, 2006).

\subsection{Prácticas cartográficas y geografias criticas}

La tercera contribución inspirada por el pensamiento feminista es la llamada a reclamar las prácticas cartográficas como una herramienta crítica. Esta 
demanda recupera una idea ya planteada hace unos años por Donna Haraway (1991) como parte de su propuesta en torno a la idea del cíborg. En el contexto tecnológico actual, la ocupación de una posición híbrida entre tecnología y humanidad es importante porque permite reivindicar unas relaciones libres de dominación. Para Haraway, reclamar el uso propio e interesado de las tecnologías visuales por parte de los colectivos oprimidos resulta crucial ya que, si bien hasta ese momento habrían permitido a los que estaban en el poder afirmar su mirada como única autoridad, también podían servir a otros objetivos, aunque inicialmente fuera desde una posición crítica y marginal. Para ello, las mujeres deben reapropiarse de aquellas herramientas y tecnologías útiles para situarlas en posiciones de poder social. El uso activo de los mapas y los SIG se convertiría así en un «acto político» de resistencia y transformación social mucho más efectivo, tanto desde un punto de vista epistemológico como ontológico (Schuurman, 2002). De esta forma, aunque las prácticas cartográficas puedan servir para desarrollar análisis más sensibles y complejos de los lugares y las identidades urbanas, cuando son utilizados de manera convencional pueden llegar a ejercer una "violencia epistémica» contra aquellos colectivos vulnerables, al presentar sus experiencias de manera reducida o estigmatizada (Parker, 2016a). Esta ha sido, de hecho, una de las mayores aportaciones de la teoría feminista con relación a lo visual: no existe un único modo de ver el mundo ni existe un único mapa o representación del territorio, sino distintas miradas y combinaciones de "perspectivas individuales, sociales, científicas y tecnológicas» (Kwan, 2002b: 648) que permiten imaginar otras formas de ver y representar la realidad. Además, cada mirada tiene unos efectos sociales determinados (G. Rose, 2011).

Pavlovskaya (2002; 2004), por ejemplo, ha investigado algunos aspectos de las «múltiples economías» de los hogares de Moscú resultantes de las transformaciones urbanas del postsocialismo. A través de la representación de la información etnográfica recogida mediante entrevistas en profundidad a un grupo de mujeres (solas o viviendo en pareja), se evidencia el peso que han tenido las actividades económicas informales para complementar los ingresos de los empleos formales en este contexto socioeconómico particular (figura 4). También visibiliza la importancia de toda una red de contactos y lazos familiares y de amistad para la economía doméstica de los hogares no convencionales (mujeres solas con hijos) que permite cubrir las tareas infravisibilizadas de los cuidados y sobrevivir en la nueva economía de mercado. Estas «otras transiciones» han sido en cierto modo ignoradas en las aproximaciones macroeconómicas sobre la transición en Rusia, y su representación permite plantear unas ontologías sociales alternativas, capaces de visibilizar fenómenos, relaciones y paisajes normalmente invisibles en los métodos y representaciones cartográficas convencionales. Poder verlas en un mapa las convierte en «reales»: la autoridad y legitimidad de aparecer en los mapas las convierte en significativas tanto de manera teórica como política (Pavlovskaya, 2009b).

Además, a través de los mapas, podemos considerar de manera conjunta las importantes relaciones que existen entre las experiencias individuales y aquellos 
Figura 4. «Múltiples economías» (prácticas económicas formales e informales) en algunos hogares del centro de Moscú, 1989 y 1995

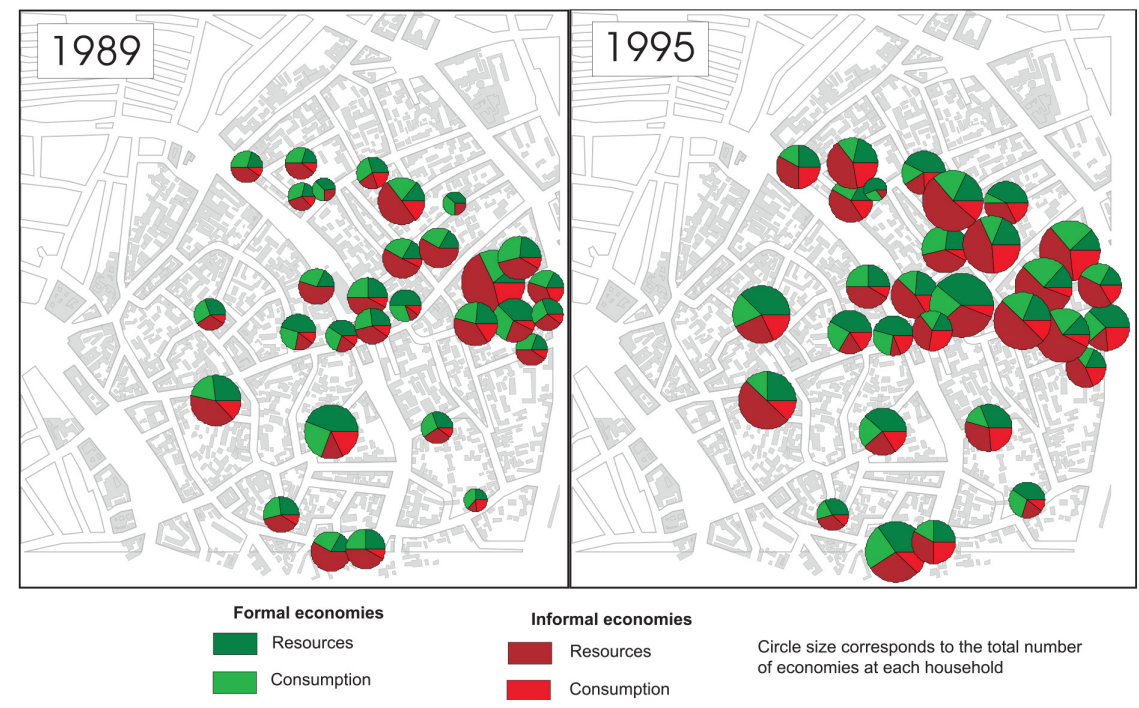

Fuente: Pavlovskaya (2004: 344).

procesos de carácter estructural que nos afectan a todas las personas. Autoras como Brenda Parker defienden, por ejemplo, la necesidad de ocupar, desde un punto de vista feminista, otro tipo de escalas de análisis urbano más amplias y normalmente relegadas en las investigaciones feministas, más habituadas a centrarse en lo próximo y lo cotidiano, porque permiten explorar como estas están conectadas entre distintos espacios y a distintas escalas (Parker, 2016b; Werner et al., 2017). De una manera más metafórica, Cindi Katz proponía, hace unos años, desarrollar un método de investigación "contratopográfico» de la globalización capaz de poner en relación espacios geográficos distantes sobre la base de problemas o intereses comunes (Katz, 2001). Esto permitiría contrarrestar otro tipo de «relatos», más extendidos y visibles, que han ignorado de manera sistemática las relaciones de género, de raza u otras relaciones de poder en los análisis geográficos.

Este es precisamente el objetivo del proyecto ciudadano «Anti-Eviction Mapping Project» en San Francisco, que desde el año 2013 trata de denunciar y exponer las consecuencias que han tenido algunas leyes y proyectos urbanísticos sobre la población más vulnerable de la ciudad (AEMP, 2018). Junto a la visualización cartográfica de datos estadísticos sobre el fenómeno de los desahucios, uno de los objetivos de su proyecto «Narrativas de la expulsión y la resistencia» ha querido utilizar las visualizaciones geográficas para adoptar una aproximación más personal y cualitativa de la problemática a través de la visualización de la historia oral desde el punto de vista de sus protagonis- 
Figura 5. Testimonios de la especulación urbanística en San Francisco y localización de todos los desalojos localizados por la organización

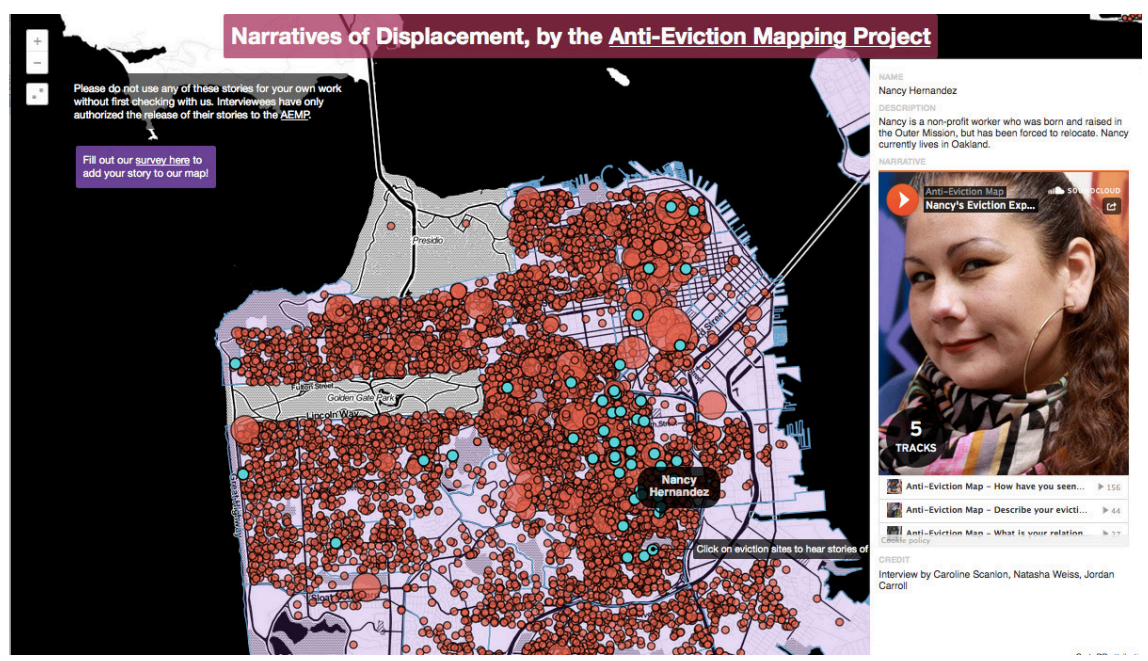

Fuente: Antieviction Mapping Project. Disponible en: <https://www.antievictionmap.com/index\#/narrativesof-displacement/>. [Consultado el 14 de julio de 2019]

tas (aquellos expulsados de sus casas o en situación de riesgo), para ayudar a construir redes de solidaridad y cooperación, conectando al mismo tiempo los lugares de resistencia con los procesos de especulación urbanística (figura 5).

\section{Reflexiones finales}

A lo largo del artículo hemos podido constatar las nuevas posibilidades que han surgido en los últimos años respecto a las prácticas cartográficas gracias a las innovaciones digitales, pero también a las reflexiones y aportaciones de colectivos relacionados de manera indirecta con la cartografía y los SIG que han empezado a utilizar los mapas de manera crítica y alternativa. Las aportaciones feministas que hemos identificado en este artículo suponen una oportunidad para repensar el modo en que entendemos y utilizamos las prácticas cartográficas actuales. Como demuestran los ejemplos descritos en el artículo, los mapas pueden llegar a ser herramientas de investigación compatibles con los principios y preocupaciones feministas y críticas. Para aprovechar este potencial es necesario repensar nuestras prácticas cartográficas. Por un lado, entendiendo los mapas como prácticas sociales cruciales ante los retos y problemas que preocupan a una gran parte de la geografía humana. Los mapas no son únicamente una tecnología, sino también una metodología y una práctica social situada en un contexto sociocultural específico. La representación cartográfica del territorio implica un complejo proceso de abstracción que produce una imagen simplificada y limitada de la realidad a través de un conjunto de deci- 
siones sobre qué elementos serán incluidos o no, qué categorías y ámbitos se utilizarán para agregar la información y cómo se traducirán estos datos a un lenguaje gráfico. Adoptar una actitud reflexiva ante los procesos de selección, generalización y simbolización cartográfica que considere de manera crítica el contexto, los intereses, la ideología y las tecnologías implicadas en la producción y utilización del mapa resulta vital para identificar los múltiples lugares desde los que los mapas influyen en nuestras ideas sobre la desigualdad, la opresión o la representación de las diferencias sociales. Estos lugares no se limitan al momento de su producción, ni de la propia representación, sino también a todo el conjunto de usos efectos y consecuencias que tienen los mapas sobre nuestras vidas. Incorporar otras metodologías y fuentes de datos cualitativos, que permitan contraponer distintas visiones y miradas sobre el territorio analizado aceptando las diferencias y la multiplicidad de experiencias que coexisten en cada lugar, puede ser una estrategia útil para una comprensión más profunda de los problemas sociales analizados.

Finalmente, es crucial identificar los efectos y las consecuencias de nuestras decisiones al estudiar y representar los problemas a través de mapas y los SIG. Los mapas no solo son una manera de representar la realidad, sino que además tienen la capacidad para configurar nuestra comprensión de los espacios y pueden llegar a influir en la propia realidad material. Aquello que no aparece en los mapas en cierto modo no existe. Así, reclamar el poder de los mapas como una herramienta crítica y emancipadora y entender el proceso cartográfico como un acto político implica la apropiación y la utilización de los mapas por parte de aquellas investigadoras y colectivos que pueden encontrar en este lenguaje particular una estrategia eficaz para dar voz a sus demandas y miradas situadas y particulares, y así desenmascarar los intereses que aprovechan la mirada cartográfica para naturalizar determinadas formas de opresión y desigualdad.

\section{Referencias bibliográficas}

AEMP (2018). Handbook by The Anti-Eviction Mapping Project (AEMP). Creating Social Change Through Creativity. Nueva York: Springer. <https://doi.org/10.1007/978-3-319-52129-9_16>

Barnes, Trevor J. (2009). "Not Only... but Also": Quantitative and Critical Geography». The Professional Geographer, 61 (3), 292-300. <https://doi.org/10.1080/00330120902931937>

Benach, Núria (2017). William Bunge: Las Expediciones Geográficas Urbanas. Barcelona: Icaria.

Bondi, Liz y Domosh, Mona (1992). «Other Figures in Other Places: On Feminism, Postmodernism and Geography». Environment and Planning D: Society and Space, 10 (2), 199-213. $<$ https://doi.org/10.1068/d100199>

Boschmann, E. Eric y Cubbon, Emily (2014). «Sketch Maps and Qualitative GIS: Using Cartographies of Individual Spatial Narratives in Geographic Research». The Professional Geographer, 66 (2), 236-248.

$<$ https://doi.org/10.1080/00330124.2013.781490> 
Brown, Michael y Knopp, Larry (2006). «Places or Polygons? Governmentality, Scale, and the Census in the Gay and Lesbian Atlas». Population, Space and Place, 12 (4), 223-242. <https://doi.org/10.1002/psp.410>

- (2008). "Queering the Map: The Productive Tensions of Colliding Epistemologies». Annals of the Association of American Geographers, 98 (1), 40-58. <https://doi.org/10.1080/00045600701734042>

Cieri, Marie (2003). «Between Being and Looking Queer Tourism Promotion and Lesbian Social Space in Greater Philadelphia». ACME: An International Journal for Critical Geographies, 2 (2), 147-66. Disponible en: <https://www.acme-journal. org/index.php/acme/article/view/691>.

Cope, Meghan y Elwood, Sarah (2009). Qualitative GIS: A Mixed Methods Approach. SAGE.

Cosgrove, Denis E. (1984). Social Formation and Symbolic Landscape. London: Croom Helm.

Crampton, Jeremy W. y Krygier, John (2005). «An Introduction to Critical Cartography». ACME: An International E-Journal for Critical Geographies 4 (1), 11-33. Disponible en: <https://www.acme-journal.org/index.php/acme/article/view/723>.

D’Ignazio, Catherine y Klein, Lauren F. (2016). "Feminist Data Visualization». IEEE Vis Conference.

Dodge, Martin y Perkins, Chris (2008). «Reclaiming the map: British geography and ambivalent geographic practice». Environment and Planning A, 40 (6), 1271-1276. <https://doi.org/10.1068/a4172>

England, Kim V. L. (1994). «Getting Personal: Reflexivity, Positionality, and Feminist Research». The Professional Geographer, 46 (1), 80-89. <https://doi.org/10.1111/j.0033-0124.1994.00080.x>

FonT-CASASECA, Núria (2016). «Mapas contra la injusticia urbana: la utopía pragmática de la Hull House en Chicago a finales del siglo XIX». XIV Coloquio Internacional de Geocritica. Las Utopias y La Construcción de La Sociedad Del Futuro, 2-7.

Foucault, Michel (1980). Power/Knowledge: Selected Interviews and Other Writings, 1972-1977. Nueva York: Pantheon.

Garcia Ramon, Maria Dolors (1989). "Género, espacio y entorno: ¿hacia una renovación conceptual de la geografía? Una introducción». Documents d'Anàlisi Geogràfica, 14, 7-13.

Gibson-Graham, Julie-Kathy (1994). “"Stuffed If I Know!”: Reflections on Post modern Feminist Social Research». Gender, Place and Culture: A Journal of Feminist Geography, 1 (2), 205-224. <https://doi.org/10.1080/09663699408721210>

Gieseking, Jen Jack (2013). "Queering the Meaning of "Neighbourhood": Reinterpreting the Lesbian-Queer Experience of Park Slope, Brooklyn, 1983-2008». En: Queer Presences and Absences, 178-200. Berlín: Springer. <https://doi.org/10.1057/9781137314352_10>

Gilbert, Melissa R. (2005). “"Race”, Space, and Power: The Survival Strategies of Working Poor Women». En: Lin, J. y Mele, C. (eds.). (2013). The Urban Sociology Reader. London: Routledge. <https://doi.org/10.4324/9780203103333>

Glaser, Barney G.; STrauss, Anselm L. y Strutzel, Elizabeth (1968). «The Discovery of Grounded Theory; Strategies for Qualitative Research». Nursing Research, 17 (4), 364. <https://doi.org/10.1097/00006199-196807000-00014> 
Hägerstrand, T. (1970). "What about People in Regional Science». Papers of the Regional Science Association, 24, 7-21. <https://doi.org/10.1007/bf01936872>

Haraway, Donna (1988). «Situated Knowledges: The Science Question in Feminism and the Privilege of Partial Perspective». Feminist Studies, 14 (3), 575-599. <https://doi.org/10.2307/3178066>

- (1991). Simians, Cyborgs, and Women. Nueva York: Routledge.

Harris, Leila M. y Hazen, Helen D. (2005). «Power of Maps: (Counter)Mapping for Conservation». ACME: An International E-Journal for Critical Geographies, 4 (1), 99-130. Disponible en: <http://hdl.handle.net/2429/63618>.

Hoggart, Keith; Lees, Loretta y Davies, Anna (2002). Researching Human Geography. Londres: Arnold, A Member of the Hodder Headline Group.

Katz, Cindi (1996). "Towards Minor Theory». Environment and Planning D: Society and Space, 14 (4), 487-499. <https://doi.org/10.1068/d140487>

- (2001). "On the Grounds of Globalization: A Topography for Feminist Political Engagement». Signs: Journal of Women in Culture and Society, 26 (4), 1.213-1.234. $<$ https://doi.org/10.1086/495653>

KNIgge, LaDona y Cope, Meghan (2006). «Grounded Visualization: Integrating the Analysis of Qualitative and Quantitative Data through Grounded Theory and Visualization». Environment and Planning A, 38 (11), 2021-2037. <https://doi.org/10.1068/a37327>

- (2009). "Grounded Visualization and Scale: A Recursive Analysis of Community Spaces». En: Cope, Meghan y Elwood, Sarah. Qualitative GIS: A Mixed Methods Approach. Sage Publications Ltd.

$<$ https://doi.org/10.4135/9780857024541.n6>

Kobayashi, Audrey (1994). "Coloring the Field: Gender, "Race" and the Politics of Fieldwork». The Professional Geographer, 46 (1), 73-80. <https://doi.org/10.1111/j.0033-0124.1994.00073.x>

- (1997). «The Paradox of Difference and Diversity (or, Why the Threshold Keeps Moving)». En: Thresholds in Feminist Geography: Difference, Methodology, and Representation, 3-9. Lanham: Rowman \& Littlefield Publishers.

Kwan, Mei-Po (1999). "Gender and Individual Access to Urban Opportunities: A Study Using Space-Time Measures». The Professional Geographer, 51 (2), 211-227. <https://doi.org/10.1111/0033-0124.00158>

- (2002a). "Is GIS for Women? Reflections on the Critical Discourse in the 1990s». Gender, Place and Culture: A Journal of Feminist Geography, 9 (3), 271-279. <https://doi.org/10.1080/0966369022000003888>

- (2002b). "Feminist Visualization: Re-Envisioning GIS as a Method in Feminist Geographic Research». Annals of the Association of American Geographers, 92 (4), 645-661. <https://doi.org/10.1111/1467-8306.00309>

- (2004). «Beyond Difference: From Canonical Geography to Hybrid Geographies». Annals of the Association of American Geographers, 94 (4), 756-763.

- (2007). «Affecting Geospatial Technologies: Toward a Feminist Politics of Emotion». The Professional Geographer, 59 (1), 22-34. <https://doi.org/10.1111/j.1467-9272.2007.00588.x> 
- (2008). «From Oral Histories to Visual Narratives: Re-Presenting the Post-September 11 Experiences of the Muslim Women in the USA». Social \& Cultural Geography, 9 (6), 653-669. <https://doi.org/10.1080/14649360802292462>

Kwan, Mei-Po y Ding, Guoxiang (2008). «Geo-Narrative: Extending Geographic Information Systems for Narrative Analysis in Qualitative and Mixed-Method Research». The Professional Geographer, 60 (4), 443-465. <https://doi.org/10.1080/00330120802211752>

Kwan, Mei-Po y Schwanen, Tim (2016). "Geographies of Mobility». Annals of the American Association of Geographers, 106 (2), 243-256. <https://doi.org/10.1080/24694452.2015.1123067>

Leszczynski, Agnieszka (2009). "Quantitative Limits to Qualitative Engagements: GIS, Its Critics, and the Philosophical Divide». The Professional Geographer, 61 (3), 350-365. <https://doi.org/10.1080/00330120902932026>

MacEachren, A. M. y KraAk, M. J. (2001). "Research Challenges in Geovisualization». Cartography and Geographic Information Science, 28 (1), 3. <https://doi.org/10.1559/152304001782173970>

Martin, Ron (2000). Editorial: In Memory of Maps, 25. Blackwell Publishing; The Royal Geographical Society (with the Institute of British Geographers).

Matthews, Stephen A.; Detwiler, James E. y Burton, Linda M. (2005). «GeoEthnography: Coupling Geographic Information Analysis Techniques with Ethnographic Methods in Urban Research». Cartographica: The International Journal for Geographic Information and Geovisualization, 40 (4), 75-90. <https://doi.org/10.3138/2288-1450-w061-r664>

McLafferty, Sara L. (1995). "Counting for Women». The Professional Geographer, 47 (4), 436-442.

<https://doi.org/10.1111/j.0033-0124.1995.00436.x>

- (2010). «Mapping Women's Worlds: Knowledge, Power and the Bounds of GIS». Gender, Place \&. Culture, 9 (3), 263-269. <https://doi.org/10.1080/0966369022000003879>

Mennis, Jeremy; Mason, Michael J. y CaO, Yinghui (2013). «Qualitative GIS and the Visualization of Narrative Activity Space Data. International Journal of Geographical Information Science, 27 (2), 267-291. <https://doi.org/10.1080/13658816.2012.678362>

Monk, Janice y Garcia Ramon, Maria Dolors (1987). «Geografía feminista: una perspectiva internacional». Documents d'Anàlisi Geogràfica, 10, 147-157.

Monk, Janice y Hanson, Susan (1982). «On Not Excluding Half of the Human in Human Geography». The Professional Geographer, 34 (1), 11-23. <https://doi.org/10.1111/j.0033-0124.1982.00011.x>

Moss, Pamela (1995). «Embeddedness in Practice, Numbers in Context: The Politics of Knowing and Doing». The Professional Geographer, 47 (4), 442-449. <https://doi.org/10.1111/j.0033-0124.1995.00442.x>

Nast, Heidi J. (1998). «The body as 'place' Reflexivity and fieldwork in Kano, Nigeria». En: H. NASt, Heidi J. y Pile, Steve (eds.). Places through the body. Londres: Routledge, 93-116.

PArker, Brenda (2016a). «The Feminist Geographer as Killjoy: Excavating Gendered Urban Power Relations». The Professional Geographer, 69 (2), 321-328. <https://doi.org/10.1080/00330124.2016.1208513> 
- (2016b). «Feminist Forays in the City: Imbalance and Intervention in Urban Research Methods». Antipode, 48 (5), 1.337-1.358. <https://doi.org/10.1111/anti.12241>

Pavlovskaya, Marianna (2002). «Mapping Urban Change and Changing GIS: Other Views of Economic Restructuring». Gender, Place and Culture: A Journal of Feminist Geography, 9 (3), 281-289. <https://doi.org/10.1080/0966369022000003897>

- (2004). «Other Transitions: Multiple Economies of Moscow Households in the 1990s». Annals of the Association of American Geographers, 94 (2), 329-351. <https://doi.org/10.1111/j.1467-8306.2004.09402011.x>

- (2006). «Theorizing with GIS: A Tool for Critical Geographies?». Environment and Planning A, 38 (11), 2003-2020. <https://doi.org/10.1068/a37326>

- (2009a). «Feminist Visualization». En: Kitchin, Rob y Thrift, Nigel. International Encyclopedia of Human Geography, 157-164. Oxford: Elsevier. <https://doi.org/10.1016/B978-008044910-4.00556-3>

- (2009b). «Non-Quantitative GIS». En: Cope, Meghan y Elwood, Sarah. Qualitative GIS: A Mixed Methods Approach. Sage Publications Ltd.

Pavlovskaya, Marianna y St Martin, Kevin (2007). «Feminism and Geographic Information Systems: From a Missing Object to a Mapping Subject». Geography Compass, 1 (3), 583-606. <https://doi.org/10.1111/j.1749-8198.2007.00028.x>

Peluso, Nancy Lee (1995). "Whose Woods Are These? Counter-Mapping Forest Territories in Kalimantan, Indonesia». Antipode, 27 (4), 383-406. <https://doi.org/10.1111/j.1467-8330.1995.tb00286.x>

Pickles, John (ed.) (1995). Ground Truth: The Social Implications of Geographic Information Systems. Nueva York: Guilford Press.

- (2004). A History of Spaces : Cartographic Reason, Mapping, and the Geo-Coded World. London [etc.]: Routledge.

Preston, Bryan y Wilson Matthew W. (2014). "Practicing GIS as Mixed Method: Affordances and Limitations in an Urban Gardening Study». Annals of the Association of American Geographers, 104 (3), 510-529. <https://doi.org/10.1080/00045608.2014.892325>

RaIsz, Erwin (1948). General Cartography. 2a ed. Nueva York: McGraw-Hill Book Co.

Rocheleau, Dianne (1995). "Maps, Numbers, Text, and Context: Mixing Methods in Feminist Political Ecology». The Professional Geographer, 47 (4), 458-466.

Rose, Damaris (1993). "On Feminism, Method and Methods in Human Geography: An Idiosyncratic Overview». The Canadian Geographer/Le Géographe Canadien, 37 (1), 57-61.

<https://doi.org/10.1111/j.1541-0064.1993.tb01543.x>

Rose, Gillian (1993). Feminism and Geography : The Limits of Geographical Knowledge. Minneapolis: University of Minnesota Press.

- (2003). «On the Need to Ask How, Exactly, Is Geography "Visual”?». Antipode, 35 (2), 212-221. <https://doi.org/10.1111/1467-8330.00317>

- (2011). Visual Methodologies: An Introduction to Researching with Visual Materials. Londres: SAGE Publications Limited. 
SAID, Edward (1978). Orientalism: Western Representations of the Orient. Nueva York: Pantheon.

Sauer, Carl O. (1956). "The Education of a Geographer». Annals of the Association of American Geographers, 46 (3), 287-299. <https://doi.org/10.1111/j.1467-8306.1956.tb01510.x>

Schoepfer, Isabelle y Rogers, Stephanie R. (2014). «A New Qualitative GIS Method for Investigating Neighbourhood Characteristics Using a Tablet». Cartographica: The International Journal for Geographic Information and Geovisualization, 49 (2), 127-143.

<https://doi.org/10.3138/carto.49.2.1810>

Schuurman, Nadine (2000). «Trouble in the Heartland: GIS and Its Critics in the 1990s». Progress in Human Geography, 24 (4), 569-590. <https://doi.org/10.1191/030913200100189111>

- (2002). "Women and Technology in Geography: A Cyborg Manifesto for GIS. (Focus: Equity for Women in Geography)». The Canadian Geographer, $46(3), 258$.

<https://doi.org/10.1111/j.1541-0064.2002.tb00748.x>

SeAger, Joni (2001). Atlas del Estado de la Mujer en el Mundo. Madrid: Ediciones Akal.

- (2018). La Mujer en el Mundo. Atlas de la Geografía Feminista. Barcelona: Grijalbo.

Sheppard, Eric; Couclelis, Helen; Graham, Stephen; Harrington, J. W. y OnsRUD, Harlan (1999). "Geographies of the Information Society». International Journal of Geographical Information Science, 13 (8), 797-823.

<https://doi.org/10.1080/136588199241021>

Smith, Neil (1979). "Geography, Science and Post-Positivist Modes of Explanation». Progress in Geography, 3 (3), 356-383.

<https://doi.org/10.1177/030913257900300302>

Suchan, Trudy A. y Brewer, Cynthia A. (2000). «Qualitative Methods for Research on Mapmaking and Map Use». The Professional Geographer, 52 (1), 145-154. <https://doi.org/10.1111/0033-0124.00212>

Thatcher, Jim; Bergmann, Luke; Ricker, Britta; Rose-Redwood, Reuben; O'Sullivan, David; Barnes, Trevor J.; Barnesmoore, Luke R. et al. (2015). «Revisiting Critical GIS». Environment and Planning A, 48 (5). <https://doi.org/10.1177/0308518X15622208>

Vaiou, Dina y Lykogianni, Rouli (2006). «Women, Neighbourhoods and Everyday Life». Urban Studies, 43 (4), 731-743. <https://doi.org/10.1080/00420980600597434>

Valentine, Gill (2007). «Theorizing and Researching Intersectionality: A Challenge for Feminist Geography». The Professional Geographer, 59 (1), 10-21. <https://doi.org/10.1111/j.1467-9272.2007.00587.x>

Valentine, Gill y SAdGrove, Joanna (2012). «Lived Difference: A Narrative Account of Spatiotemporal Processes of Social Differentiation». Environment and Planning A, 44 (9), 2.049-2.063. $<$ https://doi.org/10.1068/a44491>

Verd, Joan Miquel y Porcel, Sergio (2012). «An Application of Qualitative Geographic Information Systems (GIS) in the Field of Urban Sociology Using ATLAS. Ti: Uses and Reflections». Forum Qualitative Sozialforschung/Forum: Qualitative Social Research, 13 (2). <http://dx.doi.org/10.17169/fqs-13.2.1847> 
WatTs, Paul R. (2010). «Mapping Narratives: The 1992 Los Angeles Riots as a Case Study for Narrative-Based Geovisualization». Journal of Cultural Geography, 27 (2), 203-227. <https://doi.org/10.1080/08873631.2010.494401>

Werner, Marion; Strauss, Kendra; Parker, Brenda; Orzeck, Reecia; Driscoll Derickson, Kate y Bonds, Anne (2017). «Feminist Political Economy in Geography: Why Now, What Is Different, and What For?». Geoforum, 79, 1-4. <https://doi.org/10.1016/j.geoforum.2016.11.013> 
